\title{
Smart Construction Logistics Governance A systems view of construction logistics in urban development
}

\author{
Mats JANNÉ, Linköping University, Sweden \\ Anna FREDRIKSSON, Linköping University, Sweden \\ Monica BILLGER, Chalmers University, Sweden \\ Nicolas BRUSSELAERS, Vrije Universiteit Brussels, Belgium \\ Selamawit Mamo FUFA, SINTEF, Norway \\ Rodrigue AL FAHEL, Closer, Sweden \\ Koen Mommens, Vrije Universiteit Brussels, Belgium
}

\begin{abstract}
To reduce disturbances and impact from construction transports during urban development, logistics flows need to be managed and controlled efficiently. One way to do so is using construction logistics setups. However, these rarely take both initiator and end-user perspectives into consideration. The paper builds on a longitudinal multiple-case study with cases from Belgium, Norway, and Sweden. The cases provide insights on different tools and approaches for gathering stakeholder input, simulation and forecasting of transport volumes, what type of services are needed in urban construction projects, and different governance measures and incentives. A cross-case analysis was performed to find similarities and differences between the countries. The result of the study is a conceptual framework, presenting a systems overview of the decision routes in urban development linked to construction logistics.
\end{abstract}

\section{Keywords}

Urban development, Construction logistics, Governance measures, Multiple-case study

\section{Introduction}

The growth of the urban population leads to increased demand for construction and renovation works in cities. Housing, public utilities, retail spaces, offices, and infrastructure projects are needed to meet the increasing number of residents and visitors, urban functions, and changing standards. While construction projects contribute to more attractive, sustainable, and economically viable urban areas, a vast amount of construction materials needs to be delivered to site. According to Guerlain et al. (2019), a construction site receives 2-10 deliveries or 8-10 tonnes of material per day. The impact of construction transport and urban development logistics is thus significant and, according to Guerlain et al. (2019), accounts for at least $30 \%$ of urban freight transports and impacts the surrounding community negatively (e.g. congestion, emissions, noise, use of public space, accidents) if not managed appropriately. With urbanisation, the amount of construction transport, and its related disturbances, is likely to increase (Deloison et al., 2020). Thus, there is a need to minimise the disturbances and emissions caused by construction logistics.

One course of action is to decrease the number of construction transports or adapt their routing through planning. Transport planning is dependent on the planning of the construction works, but also on the city's urban planning and existing legislation. Furthermore, construction transports are not independent 
from the rest of the urban logistics system and actions taken in other parts of the logistics system can severely impact the total number of transport movements and thereby the overall transport system's efficiency. The latter is essential to reach UN SDG13 (taking urgent action to combat climate change and its impacts) for which improved planning shows great potential to increase transport efficiency (Eriksson, 2019). One often utilized approach to plan and control construction logistics activities is to employ construction logistics setups (CLSs). However, these initiatives rarely consider that end-users of the CLS, i.e., contractors, prioritize other goals than reduced disturbances. These perspectives clash as an overview is missing of the interactions and decisions taken during urban development that affect and are affected by construction logistics planning and management. The purpose of this paper is to develop a Smart Construction Logistics Governance Framework, providing a systems overview and guidance on tools to be used when deciding how to organize construction logistics in urban development.

The result of the study is a conceptual framework, presenting a systems overview of the decision routes in urban development linked to construction logistics. Additionally, the framework provides guidance for developing construction logistics tools in a multi-layered urban development governance setting.

The paper is structured as follows; after this introductory chapter, a literature review of construction logistics in urban development is presented. Thereafter, the research approach is presented, including a description of the cases included in the longitudinal study this paper builds on. This is followed by the cross-case analysis. Finally, a discussion is provided, and conclusions are presented.

\section{Construction logistics in urban development}

The construction industry is characterized by projects normally being built around temporary organizations and relationships, and each new project is seen as unique (Agapiou et al., 1998b). For each of these projects, contractors, sub-contractors, consultants, builders' merchants and logistics operators are tendered and procured (Kristiansen et al., 2005), building temporary network structures to ensure that resources are in place when needed (Karrbom Gustavsson and Hallin, 2015). These network structures are characterized as two-fold (Dubois and Gadde, 2002); within the project the networks are tight, whereas between parent company and project, the network is much looser. In urban development projects, municipal authorities create an additional layer in the structure (Eriksson et al., 2021), stipulating what can built, and how. This layer sets the tone of the possible construction logistics setups (CLS) that can be utilized in urban development.

Houses and infrastructure projects are dependent on that that materials and resources are delivered to, and removed from, each site at the correct time (Josephson and Saukkoriipi, 2007) as the end-product is produced at the place of consumption (Ekeskär and Rudberg, 2016). In urban development these material flows take place in urban areas and the amount of traffic created by construction cannot be overlooked. Studies in Sweden, Belgium and the UK (Löfgren, 2010, Strale et al., 2015, Transport for London and OPDC, 2018) show that construction-related transport constitutes between $18 \%$ to $35 \%$ of goods-related transports in urban areas. Additionally, construction transports are part of the overall traffic system and share the same limited urban infrastructure with other road users (Dablanc, 2007). As discussed by Dablanc (2007), urban transports are subject to space limitations, municipal demands on environmental impact, noise restrictions and demands from residents and shop owners for accessibility. Previous studies, e.g., Lindholm and Blinge (2014), however noted that cities and authorities traditionally do not focus on urban goods transport strategies or coordinating the needs of different stakeholders. Instead, goods transport and logistics has been viewed as a problem for the logistics industry to solve (Lindholm and Blinge, 2014).

The construction logistics problem for cities today is not the construction materials' transports as such; it is how to ensure accessibility and mobility for stakeholders during the construction time. One way to 
manage problems related to construction transports is using CLSs such as terminals (e.g., construction logistics centres (CLC)), checkpoints or construction logistics plans (CLP). CLPs are documented plans for understanding how construction logistics should be managed (Serra and Oliveira, 2003), whereas the former two types of CLSs (CLCS and checkpoints) are more operative in their nature. The CLC aims to consolidate goods and reduce traffic to site (Hamzeh et al., 2007), while the checkpoint coordinates and distributes deliveries to site more evenly over time through planning efforts (Ekeskär and Rudberg, 2016). These setups focus primarily on material deliveries to site but can also alleviate on-site issues; having only the materials needed for installation reduces congested sectors on-site and the associated risks (Spillane et al., 2013). The operative setups can also help by providing loading and unloading zones (Transport for London, 2013), on- or off-site warehousing (Ghanem et al., 2018), logistics-based site plans (Fredriksson et al., 2021b), on- and off-site materials handling (Lindén and Josephson, 2013), waste management (Janné and Fredriksson, 2019) and site coordination (Sundquist et al., 2018). One way to assess the impact of construction logistics is to perform simulation and optimization studies for the projects (Fredriksson et al., 2021c). Agapiou et al. (1998a) highlight that the focus of any CLS is to improve coordination and communication between project stakeholders regarding materials and resource flows by acting as a logistics coordinator (LC).

Stakeholders can be defined as individuals or groups of individuals that can influence the objectives of an organization or be influenced by these objectives (Freeman, 1984). Lombardi (1997) argue that stakeholders are increasingly involved in decisions related to urban design in many cities. However, Macharis and Bernardini (2015) note that stakeholder participation regarding urban mobility and logistics is still only applied in a fragmented, limited manner. This is also the case for construction logistics (Janné and Rudberg, 2020), for which a participatory stakeholder framework for sustainable construction logistics was developed (Brusselaers et al., 2021) as part of the MIMIC project. Following the work performed in the two JPI Urban Europe research projects CIVIC (646453) and MIMIC (438.15.403), the primary construction stakeholders can be divided into authorities (national, regional, local), program, project, or portfolio actors (developers, utility owners, main contractors) and implementation actors (contractors, service providers) (Fredriksson et al., 2021a, Brusselaers et al., 2021). According to Janné and Fredriksson (2019), there is normally only one-way communication from a public body and/or the building supervisor on anticipated impacts. Effective participation requires a deeper understanding of the concerns and expectations of all stakeholders to ensure that all stakeholders have the same view of what is to be achieved (Macharis et al., 2009). Failing to include stakeholder perspectives in CLS design has led to poor rule adherence from main contractors and little understanding of the need and possible performance impact of a CLS from stakeholders such as developers, municipalities and main contractors (Eriksson et al., 2021).

\section{Research approach}

The paper builds on a longitudinal multiple-case study with cases from Norway, Sweden, and Belgium. The cases provide insights on different tools and approaches for gathering stakeholder input, simulation and forecasting of transport volumes, what type of services are needed in urban construction projects, and different governance measures and incentives.

Data was collected through interviews with contractors, developers, municipal and governmental representatives, and logistics service providers. Furthermore, on-site observations allowed for additional understanding of the logistics challenges facing urban development.

A cross-case analysis was performed to find similarities and differences between the countries. This led to a rich understanding of how construction logistics can be approached and governed in different European contexts and what knowledge should be transferred between cities regarding urban development and construction logistics. 


\subsection{The Norwegian case}

The City of Oslo's main goal and scope is to fulfil international (e.g., the Paris agreement), national (e.g., $55 \%$ emission reduction by 2030 and become carbon neutral by 2050), regional and local (e.g., $95 \%$ reductions of direct emissions by 2030 in Oslo) environmental goals and ambitions. In Oslo, non-road mobile machinery is estimated to account 7\% of the city's total GHG emissions (Bellona Europa, 2021). The City of Oslo has been a leader in using fossil free, and emission free construction strategies to address challenges and needs of projects to achieve these environmental goals and ambitions. Six of Norway's biggest cities followed Oslo in setting similar goals, to implement emission free construction requirements in all public project by 2025 and both public and private projects by 2030 .

Omsorgsbygg Oslo (OBY), now part of Oslobygg, is one of several municipal enterprises working in the construction sector, being a large property manager and building owner with more than $900,000 \mathrm{~m}^{2}$ in the portfolio, consisting of day care centres, nursing homes, fire stations, drug-related housing, and other municipal purpose properties. OBY has been one of the frontrunners in developing and realising emission free construction sites through their procurements. OBY has introduced several measures to create market through procurement including subsidising for purchasing electric machineries and testing their feasibilities through actual pilot projects. However, GHG emission reduction from construction machinery and transport of mass and waste, focusing (primarily) on technology shift (towards emission-free) rather than optimum construction logistics as the main target.

\subsection{The Swedish case}

Gothenburg is growing with the ambition of having 115000 new inhabitants in fifteen years' time. As

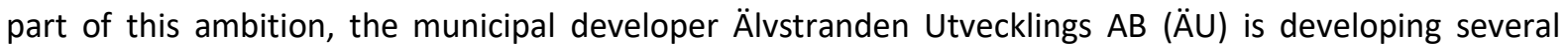
large-scale construction projects in the central parts of the city, close to other ongoing projects. Additionally, there are several other major projects underway by the city, or the state (for example, the Swedish Transport Administration, which is building the Western Link). This leads to congestion both at the entrances of, and around, the construction sites. ÄU, just like all urban planning actors, faces the great challenge of reducing the emissions that building a city generates. Since 2019, the company has the goal of halving greenhouse gas (GHG) emissions by $50 \%$ by 2024 . Additionally, there is a belief that construction logistics is a temporary problem and as soon as the project is completed, it disappears. However, given that $\ddot{A} U$ and the city of Gothenburg have many long-term projects planned and in progress, it is no longer possible to consider construction logistics as a temporary problem.

To deal with construction logistics, $\ddot{A} U$ has developed a construction logistics strategy, consisting of two parts. Part 1 aims at developing a goal for construction logistics that applies to all projects regardless of size. To achieve the goal, several possible conceptual CLSs that can streamline or improve the construction logistics in a project have been developed. Each project assesses which setup to utilize. Part 2 consists of a framework with a number of checklists that serve as support in the developing an action plan for construction logistics.

\subsection{The Belgian case}

The Belgian case concerns the mixed 'City Campus' pilot site in Brussels-Capital Region (BCR), a $17.600 \mathrm{~m}^{2}$ site for an SME park for agri-food companies and social and student residences. City Campus is organized in association with the public-private partnership between owner and city development agency CityDev and main building contractor Van Roey Vastgoed.

Due to its location in a densely populated urban area, both the construction site and the greater transport area to and from the site, show needs for a CLS. The construction site is considered as a typical 'large' construction project in Brussels, with a strong output value upon completion and the projects' location offers accessibility to a variety of relevant and potential transport entries and exits. The area is in 
proximity of a large school, public transport facilities, major road axes such as the RO ring of Brussels and the E19 highway as well as the main navigable inland waterway axes of the Brussels-Charleroi Canal and the Willebroekse Vaart. Brussels aims to meet environmental targets by reducing the impact of mobility on the environment by achieving -35\% of GHG by 2030 as compared to 2005.

The BCR is a complex web of actors, reinforced by the fact each of the 19 municipalities has its own and unique administration and legislation. Furthermore, the Anderlecht neighbourhood offers a rich diversity of stakeholders, including a shopping centre, a higher-education college, and local businesses. With many stakeholders involved and many potential conflicts, the area thus provides a good foundation for understanding stakeholder needs and the overall impact from different construction transport setups.

\section{Cross-case analysis}

All three cases show that a common goal with CLSs is to reduce the impact from construction logistics. The City of Oslo, Brussels and ÄU all have goals to reduce environmental impact based on national, regional, and EU goals on GHG emission reduction, and all three approach construction logistics partly from this perspective. Furthermore, all three cases show evidence of planning in construction logistics being perceived as hierarchical, with processes at different planning levels: strategic, tactical, and operative. Strategic planning has a long-term horizon and sets the boundaries for the mid-term horizon tactical planning, which sets the boundaries for the short-term horizon operative planning. However, the three cases also show that due to the complex relationships in the projects, planning on the three planning levels are not necessarily performed by the same actor or even with the same goal (Figure 1).

The focus in Norwegian and the Swedish case is on the strategic level, setting policies and regulatory frameworks for how to approach construction logistics. In the Norwegian case, these policies and legal frameworks are operationalised through using the strength of the municipality as a big public buyer in the procurement processes. In the Swedish case, ÄU acts as an authority in terms of setting policies for how construction logistics should be managed by their projects but leaves the actual operationalisation up to the individual projects. The Belgian case is more complex with multiple legislative entities (19 municipalities) with different approaches of how to reduce environmental impact from transports and mobility. These entities first need to consolidate their construction logistics strategies before any clear operationalised CLS can be implemented.

Both the Norwegian and the Belgian cases approach construction logistics on a tactical planning level through procurement directives following the legislation. These directives are used to procure the CLS to be operationalised. As such, the authority level has a direct impact on the development of the CLS. It can be argued however, that ÄU's strategy primarily aims at providing grounds for how to tactically plan for a CLS. They provide suggestions of different CLSs and checklists to follow when deciding on the CLS. As such, ÄU has provided different CLS scenarios that the projects can refer to in the operationalisation process but the actual operationalisation of the CLS up to the individual projects. 


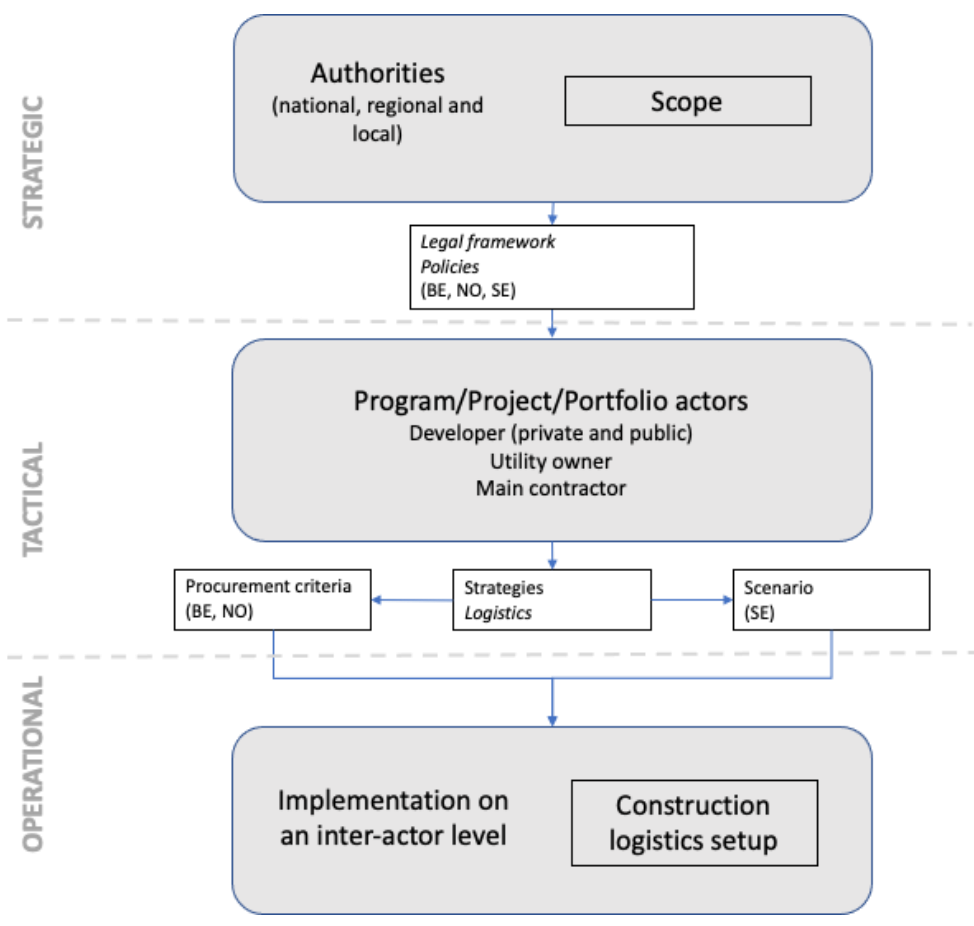

Figure 1: Case findings in the construction logistics planning levels (strategic, tactical, and operational)

\section{Concluding discussion}

Figure 2 below presents the suggested framework for CLS planning. The framework is divided into the three planning stages, highlighting the focus that each stakeholder level should focus on.

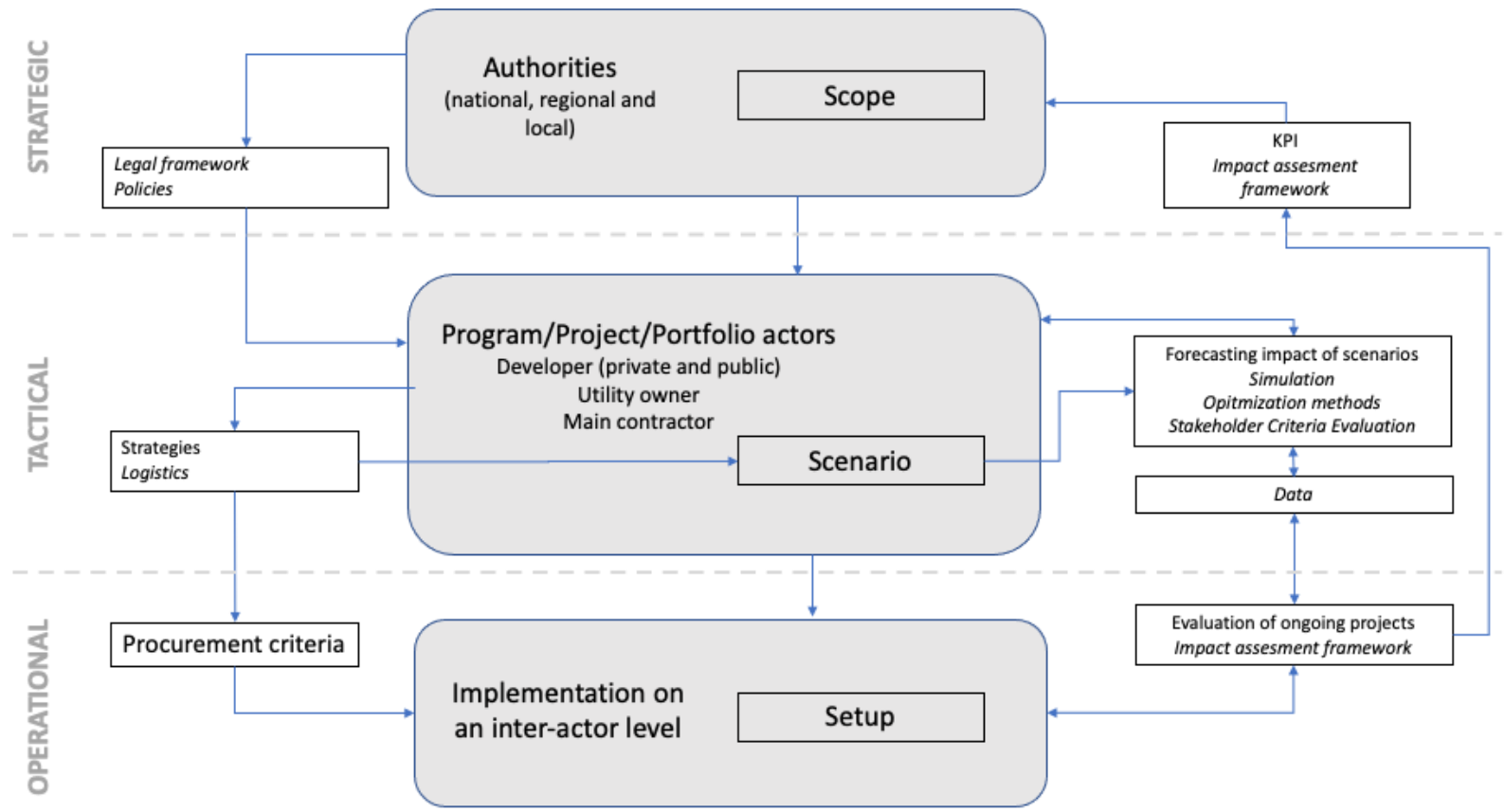

Figure 2: Suggested framework for CLS planning on strategic, tactical, and operational levels

The cases reported in this study all depart from the need to reduce impact from construction logistics activities in urban development. As such, on a strategic level, construction logistics in urban development will inherently be affected by the national, regional, and local policies and legal frameworks that are implemented in a city. These policies and legal frameworks will affect how a CLS is planned for and implemented and should lay the foundation for the CLS strategies of the program, project, and portfolio 
actors. The scope of the CLS should be set on the strategic level and strive to include clearly defined, measurable and achievable criteria with focus on logistics (Agapiou et al., 1998a). The scope should also take into consideration the work on emission free (to reduce GHG emissions), waste free (to increase efficient resource utilisation) and circular (to maximize resource reuse) construction projects. The Oslo case shows, setting ambitious level emission free construction strategies, by limiting the scope first towards achieving emission free on-site construction setups and services, enable to realise emission-free construction site (Fufa et al., 2019, Venås et al., 2020).

However, to avoid the one-way communication reported on by Janné and Fredriksson (2019), policy makers need take into consideration feedback from the industry on what policies are applicable in a construction logistics context. Partly this can be achieved by monitoring how the CLSs function in the urban transport system and what effect they have on reducing negative impact on the sustainable development of the city. As such, we propose that CLS planning includes an impact assessment framework with suitable KPIs on the tactical planning level (Brusselaers et al., 2020, Venås et al., 2020) to monitor the impact that CLSs have. This would also allow for evaluating existing CLSs to provide guidance through the policies on what possibilities are available for managing construction logistics. This would also signal that policy makers take the matter seriously, working with the industry to solve the construction logistics issues of urban development (Lindholm and Blinge, 2014).

The goal of CLS planning on the tactical level is to come up with a set of procurement criteria for the CLS that can feed into operationalization of the operational planning level. However, in order for the CLS to fit the context of the program, project or portfolio (Fredriksson et al., 2021b) we suggest that the initiators work with scenarios for different CLSs. The ÄU case show that having a set of pre-defined CLSs can allow for setting a CLS that works for the project in focus. These scenarios should include gathering information of the program, project or portfolio as well as understanding the surrounding transport situation and what is happening in the vicinity of the projects in order to be able to perform simulations and optimization of transport flows as suggested by Fredriksson et al. (2021c). Furthermore, to assess which stakeholders are affected by construction logistics and a potential CLS, the Brussels case shows that including a stakeholder impact assessment study can be a good way to gather this information (Fredriksson et al., 2021a, Brusselaers et al., 2021). This is included in the framework as a decision category when evaluating the different scenarios and deciding the CLS. Gathering information on stakeholder preferences can allow for a CLS that cater to the needs of the projects while simultaneously working towards the overall goal of reducing the negative sustainability impact that construction logistics has on the city (Eriksson et al., 2021). Evaluating the scenarios on the tactical level is, however, dependent on having data to build the evaluations from. How this data is collected and evaluated should be part of setting the tactical scope of the CLS. This includes evaluating different sensors and data collections methods to be utilized in the CLS.

The procurement criteria developed on the tactical planning level feeds into the procurement and operationalization of the CLS. What is important to note in the operationalization of the CLS is that also here it is important to include the different direct stakeholders impacted by the CLS (Eriksson et al., 2021). As noted in the Brussels and Oslo cases, many different stakeholders are affected by construction and construction logistics, so there should be an ambition to inform indirect stakeholders of the progress of a construction project and the disturbances that can occur during the time. However, getting the acceptance of the CLS is dependent on creating a sense of owned ownership amongst the direct stakeholders (Fredriksson et al., 2021b, Brusselaers et al., 2021). As part of creating this sense of ownership, current construction logistics practices and the impact that construction has on the surrounding society needs to be evaluated and fed back to the CLS organization as well as the construction projects. 
These feedback loops should also consider the procurement criteria set on the tactical level and feedback whether they are achievable. Among the main challenges is the uncertainty about availability of construction machinery and new zero emission technologies. For example, the technologies for electrical construction and logistics machinery are rapidly developing, but there is still a lack of supply. This makes it risky for the contractors to rely solely on electrical machinery, and to promise such deliveries in the tenders, even though this will give them the highest score during evaluation process. As there is no reserve capacity of electrical machinery, a delay in the project or in the delivery of machinery or machine failure can have large consequences, making the offer of electrical machinery a difficult decision during delivery of the tender.

\section{Concluding remarks}

In urban development projects, important limitations in implementing a holistic view of construction logistics are the complex organization of projects today, which are often stuck in a traditional way of thinking, especially in the early phase of the construction projects. As an aid to move the construction industry forward in terms of construction logistics, this paper has presented a framework for how to approach planning for construction logistics on the strategic, tactical, and operational planning levels. An important part in the framework is the constant involvement between different stakeholders, particularly on the strategic and operational levels, but also on the strategic level. Partly, the framework simplifies the strategic level by connecting it predominantly to the authorities. However, large developers and contractors can also work on the strategic level with setting their own construction and logistics strategies that need to trickle down to the tactical and operational levels. Future research should focus on how large companies approach construction logistics from a strategic standpoint and how this is diffused within the company, into their programs, projects, or portfolios, and to their partners, e.g. subcontractors and suppliers as well as how CLSs are implemented.

\section{References}

Agapiou, A., Clausen, L. E., Flanagan, R., Norman, G. \& Notman, D. 1998a. The role of logistics in the materials flow control process. Construction Management and Economics, 16, 131-137.

Agapiou, A., Flanagan, R., Norman, G. \& Notman, D. 1998b. The changing role of builders merchants in the construction supply chain. Construction Management and Economics, 16, 351-361.

Bellona Europa. 2021. Norwegian cities lead the way in reaching zero-emissions in construction sites [Online]. https://bellona.org/news/climate-change/2021-03-norwegian-cities-lead-the-way-in-reaching-zeroemissions-in-construction-sites: Bellona.org. [Accessed 13 May 2021].

Brusselaers, N., Mommens, K., Janné, M., Fredriksson, A., Venås, C., Flyen, C., Fufa, S. M. \& Macharis, C. 2020. Economic, social and environmental impact assessment for off-site construction logistics: the data availability issue. IOP Conference Series: Earth and Environmental Science, 588, 032030.

Brusselaers, N., Mommens, K. \& Macharis, C. 2021. Building Bridges: A Participatory Stakeholder Framework for Sustainable Urban Construction Logistics. Sustainability, 13.

Dablanc, L. 2007. Goods transport in large European cities: Difficult to organize, difficult to modernize. Transportation Research Part A: Policy and Practice, 41, 280-285.

Deloison, T., Hannon, E., Huber, A., Heid, B., Klink, C., Sahay, R. \& Wolff, C. The Future of the Last-mile Ecosystem: Transition Roadmaps for Public-and Private-sector Players. 2020. World Economic Forum.

Dubois, A. \& Gadde, L.-E. 2002. The construction industry as a loosely coupled system: implications for productivity and innovation. Construction Management and Economics, 20, 621-631.

Ekeskär, A. \& Rudberg, M. 2016. Third-party logistics in construction: the case of a large hospital project. Construction Management and Economics, 34, 174-191.

Eriksson, V. 2019. Transport Efficiency: Analysing the Transport Service Triad. Licentiate, Chalmers University.

Eriksson, V., Hulthén, K., Sundquist, V., Fredriksson, A. \& Janné, M. 2021. The role of public actors in construction logistics: Effects on and of relational interfaces. Construction Management \& Economics, ahead-of-print. 
Fredriksson, A., Janné, M., Nolz, P., De Radiguès De Chennevière, P., Van Lier, T. \& Macharis, C. 2021a. Creating stakeholder awareness in construction logistics by means of the MAMCA. City and Environment Interactions, 11.

Fredriksson, A., Janné, M. \& Rudberg, M. 2021b. Characterizing Third-Party Logistics Setups in the Context of Construction. International Journal of Physical Distribution \& Logistics Management, 51, 325-349.

Fredriksson, A., Nolz, P. C. \& Seragiotto, C. 2021c. A mixed method evaluation of economic and environmental considerations in construction transport planning: The case of Ostlänken. Sustainable Cities and Society.

Freeman, R. E. 1984. Strategic management: A stakeholder perspective. Boston: Pitman, 13.

Fufa, S. M., Wiik, M. K., Mellegård, S. \& Andresen, I. 2019. Lessons learnt from the design and construction strategies of two Norwegian low emission construction sites. IOP Conference Series: Earth and Environmental Science, 352, 012021.

Ghanem, M., Hamzeh, F., Seppänen, O. \& Zankoul, E. 2018. A New Perspective of Construction Logistics and Production Control: An Exploratory Study. In: GonzáLez, V. A. (ed.) 26th Annual Conference of the International Group for Lean Construction. Chennai, India: International Group for Lean Construction.

Guerlain, C., Renault, S. \& Ferrero, F. 2019. Understanding Construction Logistics in Urban Areas and Lowering Its Environmental Impact: A Focus on Construction Consolidation Centres. Sustainability, 11.

Hamzeh, F. R., Tommelein, I. D., Ballard, G. \& Kaminsky, P. M. 2007. Logistics Centers to Support Project-Based Production in the Construction Industry. In: Pasquire, C. L. \& Tzortzopoulos, P. (eds.) 15th Annual Conference of the International Group for Lean Construction. East Lansing, Michigan, USA.

Janné, M. \& Fredriksson, A. 2019. Construction logistics governing guidelines in urban development projects. Construction Innovation, 19, 89-109.

Janné, M. \& Rudberg, M. 2020. Effects of employing third-party logistics arrangements in construction projects. Production Planning \& Control, In press.

Josephson, P.-E. \& Saukkoriipi, L. 2007. Waste in Construction Projects: Call for a New Approach. Gothenburg, Sweden: The Centre for Management of the Built Environment, Chalmers University of Technology.

Karrbom Gustavsson, T. \& Hallin, A. 2015. Goal seeking and goal oriented projects - trajectories of the temporary organisation. International Journal of Managing Projects in Business, 8, 368-378.

Kristiansen, K., Emmitt, S. \& Bonke, S. 2005. Changes in the Danish construction sector: the need for a new focus. Engineering, Construction and Architectural Management, 12, 502-511.

Lindén, S. \& Josephson, P. E. 2013. In-housing or out-sourcing on-site materials handling in housing? Journal of Engineering, Design and Technology, 11, 90-106.

Lindholm, M. \& Blinge, M. 2014. Assessing knowledge and awareness of the sustainable urban freight transport among Swedish local authority policy planners. Transport Policy, 32, 124-131.

Lombardi, P. 1997. Decision making in urban regeneration plans. Engineering, Construction and Architectural Management, 4, 127-142.

Löfgren, P. 2010. Effektiva Byggtransporter. Stockholm, Sweden: Sveriges Byggindustrier.

Macharis, C. \& Bernardini, A. 2015. Reviewing the use of Multi-Criteria Decision Analysis for the evaluation of transport projects: Time for a multi-actor approach. Transport Policy, 37, 177-186.

Macharis, C., De Witte, A. \& Ampe, J. 2009. The multi-actor, multi-criteria analysis methodology (MAMCA) for the evaluation of transport projects: Theory and practice. Journal of Advanced Transportation, 43, 183-202.

Serra, S. \& Oliveira, O. Development of the logistics plans in building construction. INTERNATIONAL CONFERENCE ON STRUCTURAL AND CONSTRUCTION ENGINEERING, 2003.

Spillane, J. P., Cahill, G., Oyedele, L. O., Von Meding, J. \& Konanahalli, A. 2013. Supply Chain Management in Confined Site Construction: Strategies to Reduce Delay in the Delivery of Materials to Site. RICS COBRA 2013 Research Conference.

Strale, M., Lebeau, P., Wayens, B., Hubert, M. \& Macharis, C. 2015. Le transport de marchandises et la logistique à Bruxelles : état des lieux et perspectives. In: Thiry, C. (ed.) Cahiers de l'Observatoire de la mobilité de la Région de Bruxelles-Capitale. Brussels, Belgium: Bruxelles Mobilité.

Sundquist, V., Gadde, L.-E. \& Hulthén, K. 2018. Reorganizing construction logistics for improved performance. Construction Management and Economics, 1-17.

Transport for London 2013. Construction Logistics Plan Guidance for Developers. Windsor House, London, United Kingdom: Transport for London. 
Billger, M.; Fufa, S.M.; Al Fahel, R.; Mommens, K.

Transport for London \& Opdc 2018. Construction and Logistics Strategy. In: Transport for London (ed.) https://www.london.gov.uk/sites/default/files/10. construction and logistics strategy 2018.pdf. London, UK.: Transport for London,.

Venås, C., Flyen, C., Fufa, S. M., Janné, M., Fredriksson, A., Brusselaers, N., Mommens, K. \& Macharis, C. 2020. No or low emissions from construction logistics - Just a dream or future reality? IOP Conference Series: Earth and Environmental Science, 588, 042003. 